\title{
Структурные и оптические свойства нанонитей карбида кремния, полученных высокотемпературной карбидизацией кремниевых наноструктур
}

\author{
(C) А.В. Павликов ${ }^{1}$, Н.В. Латухина ${ }^{2}$, В.И. Чепурнов ${ }^{3}$, В.Ю. Тимошенко ${ }^{1,3}$ \\ ${ }^{1}$ Московский государственный университет им. М.В. Ломоносова (физический фракультет), \\ 119991 Москва, Россия \\ ${ }^{2}$ Самарский государственный аэрокосмический университет им. С.П. Королева \\ (национальный исследовательский университет), \\ 443086 Самара, Россия \\ ${ }^{3}$ Томский государственный университет (национальный исследовательский университет), \\ 634050 Томск, Россия \\ E-mail: pavlikov@physics.msu.ru
}

(Получена 15 июля 2016 г. Принята к печати 3 августа 2016 г.)

\begin{abstract}
В процессе высокотемпературной карбонизации пористого кремния и кремниевых нанонитей получены нитевидные структуры карбида кремния $(\mathrm{SiC})$ с диаметрами 40-50нм, которые были исследованы методами сканирующей электронной микроскопии, рентгеновской дифракции, комбинационного рассеяния света и спектроскопии инфракрасного отражения. Данные рентгеноструктурного анализа и спектроскопии комбинационного рассеяния света свидетельствуют, что в исследованных образцах доминирует кубический политип 3C-SiC. Форма спектра инфракрасного отражения в области полосы остаточных лучей $800-900 \mathrm{~cm}^{-1}$ указывает на присутствие свободных носителей заряда. Обсуждается возможность использования полученных нанонитей $\mathrm{SiC}$ в устройствах микроэлектроники, фотоники и газовой сенсорики.
\end{abstract}

DOI: $10.21883 /$ FTP.2017.03.44219.8370

\section{1. Введение}

Карбид кремния (SiC), благодаря ряду уникальных свойств - большой ширине запрещенной зоны (2.3-3.3 эВ для различных политипов), чрезвычайно высокому критическому полю лавинного пробоя $(2-5 \mathrm{MB} / \mathrm{cm})$, теплопроводности $(3-5 \mathrm{BT} / \mathrm{cm} \cdot \mathrm{K})$, превосходящей при комнатной температуре теплопроводность меди, химической и радиационной стойкости (за счет высокой энергии дефектообразования 25-35 эВ) является востребованным материалом для применения в различных областях современной электроники. Среди политипов $\mathrm{SiC}$ наиболее изучены 3C-SiC, 4H-SiC и $6 \mathrm{H}-\mathrm{SiC}$, которые различаются шириной запрещенной зоны, электрофизическими свойствами, в частности подвижностью носителей заряда, а также оптическими параметрами. Те модификации $\mathrm{SiC}$, которые используются в электронных устройствах, обладают большой электрической прочностью, высокими рабочими температурами, повышенной радиационной стойкостью, температурной и временно́й стабильностью электрических характеристик $[1,2]$. Использование подложек кристаллического кремния (c-Si) с пористым слоем на поверхности для создания гетероструктур $\mathrm{SiC} / \mathrm{Si}$ позволяет сочетать высокие эксплуатационные характеристики слоев $\mathrm{SiC}$ с хорошо развитой кремниевой технологией.

Наноструктурирование позволяет изменить многие физические свойства $\mathrm{SiC}$ : например, было показано, что нанотрубки $\mathrm{SiC}$ имеют еще бо́льшую механическую упругость, чем объемный материал [3]. К другим интересным свойствам наноструктур $\mathrm{SiC}$ можно отнести наличие автоэлектронной эмиссии, порог и свойства которой сопоставимы с характерными для углеродных нанотрубок [4]. Эти и многие другие свойства делают наноструктуры карбида кремния крайне привлекательными для исследования.

В последнее время проявляется огромный интерес к наноструктурам $\mathrm{SiC}$, полученным различными методами, в том числе электрохимическим травлением [5], твердофазной эпитаксией [6,7], методами пар-жидкостьтвердое тело (VLS) [4] или химического осаждения из газовой фазы (CVD) [8]. Особый интерес представляет формирование $\mathrm{SiC}$ с использованием в качестве затравки наноструктур кремния, таких как слои пористого кремния (por-Si) и кремниевые нанонити ( $\mathrm{Si}-\mathrm{NW})$, интенсивно исследуемые в последнее время $[9,10]$. Применение por-Si и $\mathrm{Si}-\mathrm{NW}$ в гетероструктурах с $\mathrm{SiC}$ позволяет решить проблему согласования кристаллических решеток гетеропары и поднять качество структур.

В нашей работе нанонити $\mathrm{SiC}$, формируемые в процессе высокотемпературной карбидизации слоев por-Si и $\mathrm{Si}-\mathrm{NW}$, исследовались структурно-чувствительными и оптическими методами. Полученные результаты свидетельствуют о доминировании кубического политипа и присутствии свободных носителей заряда в полученных нанонитях.

\section{2. Методика эксперимента}

Образцы 1,2 были получены путем карбонизации слоев por-Si, а образцы 3, 4 - карбонизацией $\mathrm{Si}-\mathrm{NW}$. 
Слои por-Si и $\mathrm{Si}-\mathrm{NW}$ на подложке $c$-Si ( $p$-тип проводимости, удельное сопротивление $\rho=10$ Ом · см) получались посредством электрохимического или химического металл-стимулированного травления сооответственно. Карбонизация осуществлялась методом химического транспорта в открытой системе твердофазных кремния и углерода с газом-носителем водородом в зону эпитаксии с последующим осаждением на кремниевых подложках с пористым слоем (por-Si либо Si-NW). Процесс проводился в потоке водорода в вертикальном водоохлаждаемом реакторе с холодными стенками. Твердофазное преобразование por- $\mathrm{Si} / \mathrm{Si}$ в por-SiC/Si происходит в среде водорода диффузионной очистки при температуpe $1360-1380^{\circ} \mathrm{C}$ со скоростью $2.5-3.5$ мкм/ч $[11,12]$. Источником твердофазных реагентов служил пористый пиролитический графит.

Полученные в данной работе образцы исследовались методами сканирующей электронной микроскопии с использованием микроскопа Carl Zeiss Supra 25-30-85. Для измерения спектров комбинационного рассеяния света (КРС) использовалась микро-рамановская установка Horiba Jobin Yvon HR800. Источником возбуждения являлся гелий-неоновый лазер (длина волны излучения $\lambda=633$ нм). Регистрация сигнала КРС производилась в конфигурации „на отражение“. В качестве детектора использовалась цифровая камера с ПЗС матрицей. Измерения спектров отражения инфракрасного излучения проводились на инфракрасном (ИК) фурье-спектрометре фирмы Bruker IFS 66v/S в среднем спектральном интервале $\left(370-7500 \mathrm{~cm}^{-1}\right)$ с разрешением $2 \mathrm{~cm}^{-1}$. Измерение спектров дифракции рентгеновских лучей проводилось с помощью порошкового рентгеновского дифрактометра Stoe Stadi P. Картины дифракции получены в геометрии „на прохождение“. В качестве источника рентгеновского излучения использовалась $K$-линия $\mathrm{Cu}$ (длина волны $\lambda=1.5418 \AA)$.

\section{3. Экспериментальные результаты}

На рис. $1, a, b$ приведены полученные методом сканирующей электронной микроскопии (СЭМ) изображения поверхности до и после процесса карбонизации пористого кремния (гетероструктуры por-SiC/Si), который по диаметру пор на поверхности (> 1 мкм) может быть отнесен к макропористому. В областях локального пересыщения газовой фазы по углероду на поверхности подложек наблюдалось образование нитевидных структур толщиной от единиц до сотни нанометров (рис. $1, b)$. Эти результаты согласуются с исследованием [10] отделенных от подложки нитевидных образований в просвечивающем электронном микроскопе, показавшим, что нановолокна толщиной 40-50нм имеют явно выраженную внутреннюю волокнистую структуру с сильно различающимися по контрасту областями толщиной в несколько ангстрем, на более тонких образованиях такая структура не выявляется. Известно, что при эпитаксии в условиях пересыщения газовой фазы углеродом в присутствии атомов кремния наряду с углеродными нанотрубками образуются нановолокна и нанотрубки карбида кремния [13-15], что, по-видимому, могло иметь место и в нашем случае.

На рис. 2 представлены спектры КРС образцов 1 и 2, сформированных на por-Si. В спектре образца 1 присутствуют линии на 520, 796 и широкая полоса в районе $960 \mathrm{~cm}^{-1}$. Первая линия, на $520 \mathrm{~cm}^{-1}$, - самая интенсивная и соответствует вырожденному однофононному рассеянию на оптических фононах кристаллической решетки $\mathrm{Si}$. Присутствие этой линии в спектре свидетельствует о проникновении возбуждающего излучения в слой por-Si. Широкая полоса в районе $960 \mathrm{~cm}^{-1}$ также обусловлена взаимодействием возбуждающего излучения с por-Si, но в данном случае это более слабый двухфононный процесс, интенсивность которого значительно меньше однофононного. Наряду с указанными двумя в спектре видна линия на $796 \mathrm{~cm}^{-1}$, сопоставимая по интенсивности с двухфононной полосой в por-Si. Она свидетельствует о взаимодействии возбуждающего излучения с поперечными оптическими (ТО) фононами в 3C-SiC.
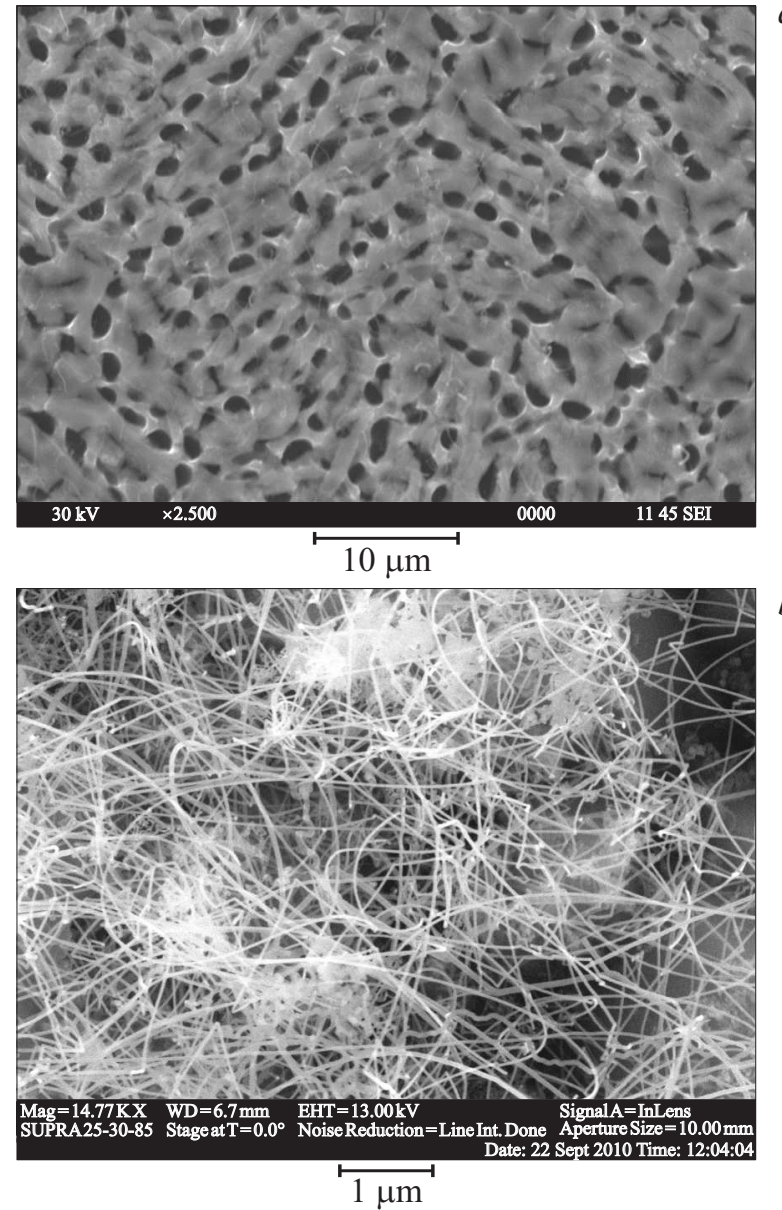

Рис. 1. Изображения, полученные в сканирующем электронном микроскопе, поверхности слоев пористого кремния до $(a)$ и после карбидизации $(b)$. 


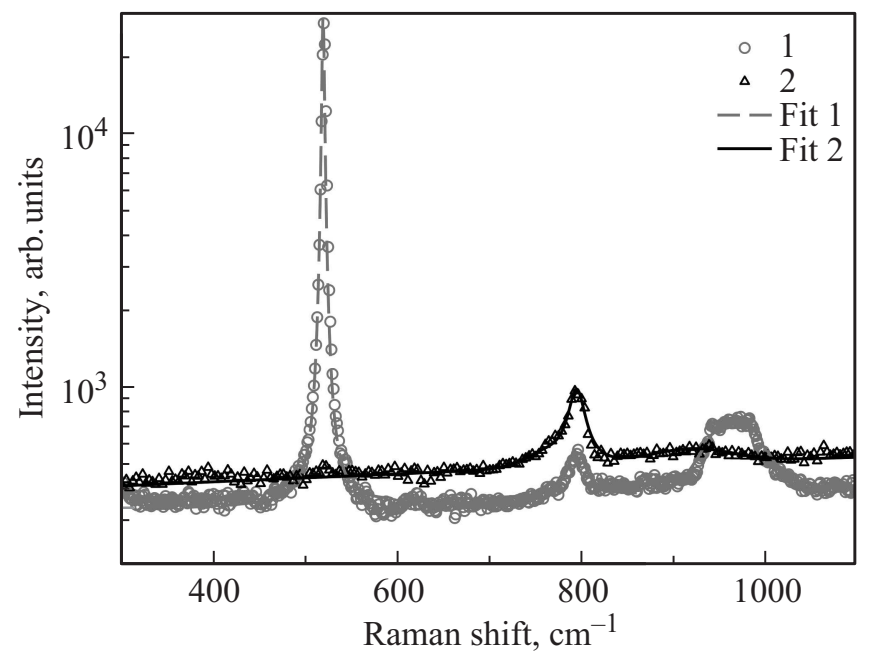

Рис. 2. Спектры КРС образцов 1,2 и результаты аппроксимации (Fit 1 и Fit 2 соответственно).

В спектре КРС образца 2 присутствует только линия на $796 \mathrm{~cm}^{-1}$. Отсутствие линий, характерных для кремния, указывает на то, что поверхность образца в этой области плотно покрыта нанонитями $\mathrm{SiC}$. Из литературы известно [16], что в кристаллическом 3C-SiC наблюдается менее интенсивная линия продольных оптических (LO) фононов на $972 \mathrm{~cm}^{-1}$, но в образцах 1 и 2 эта линия не наблюдается.

Для более детального анализа результатов было выполнено разложение экспериментального спектра на составляющие компоненты. Результат аппроксимации для образца 1 представлен на рис. 2 штриховой линией. Анализ полуширин линий на 520 и $796 \mathrm{~cm}^{-1}$ для образца 1 показывает, что линия однофононного взаимодействия в кремнии имеет полуширину $3 \mathrm{~cm}^{-1}$, а линия поперечных оптических (ТО) фононов на $796 \mathrm{~cm}^{-1}-$ около $10 \mathrm{~cm}^{-1}$. Следует отметить, что при этом не наблюдается существенного смещения максимума линии относительно $796 \mathrm{~cm}^{-1}$. На рис. 2 результат разложения для образца 2 представлен сплошной линией. В этом спектре отсутствует сигнал от $\mathrm{Si}$ и отчетливо наблюдается лишь одна линия, но компьютерное разложение показывает, что наилучшего согласия с экспериментальными результатами удается добиться, если учитывать наличие еще двух полос: с максимумом на $762 \mathrm{~cm}^{-1}$, которая, возможно, объясняется наличием аморфной составляющей, и широкой полосы с максимумом на $920 \mathrm{~cm}^{-1}$, полушириной $50 \mathrm{~cm}^{-1}$. Эту полосу авторы некоторых работ [17] по $\mathrm{SiC}$ приписывают LO-моде, но при этом они отмечают, что полоса сильно сдвинута, на $40-50 \mathrm{~cm}^{-1}$, и имеет большую полуширину, что никак нельзя описать эффектом пространственного ограничения фононов [18], а скорее может быть объяснено многочисленными дефектами упаковки кристаллической решетки и возникшими механическими напряжениями.
Спектры КРС для образцов 3 и 4 представлены на рис. 3. Для образца 3 наблюдается пик на $796 \mathrm{~cm}^{-1}$, что свидетельствует о наличии $\mathrm{SiC}$ на поверхности $\mathrm{Si}-\mathrm{NW}$. В отличие от образца 1 амплитуды пиков от Si-NW $\left(520 \mathrm{~cm}^{-1}\right)$ и нанонитей $\mathrm{SiC}\left(796 \mathrm{~cm}^{-1}\right)$ имеют одинаковый порядок. Это, по всей видимости, свидетельствует о равномерном распределении нанонитей $\mathrm{SiC}$ по поверхности Si-NW. Образец 4 имеет в спектре КРС один пик на $796 \mathrm{~cm}^{-1}$, характерный для $\mathrm{SiC}$. Анализ полуширин дает такие же результаты, как для образцов 1 и 2.

Результат разложения (см. рис. 3) показывает, что для образца 3 так же, как и для образца 1 , присутствуют линии КРС, характерные для $\mathrm{Si}$ и 3C-SiC. Однако в данном случае интенсивность однофононной моды $\mathrm{Si}$ намного слабее и сопоставима с интенсивностью $3 \mathrm{C}-\mathrm{SiC}$; следовательно, появление более слабого двухфононного взаимодействия мало вероятно. Действительно,

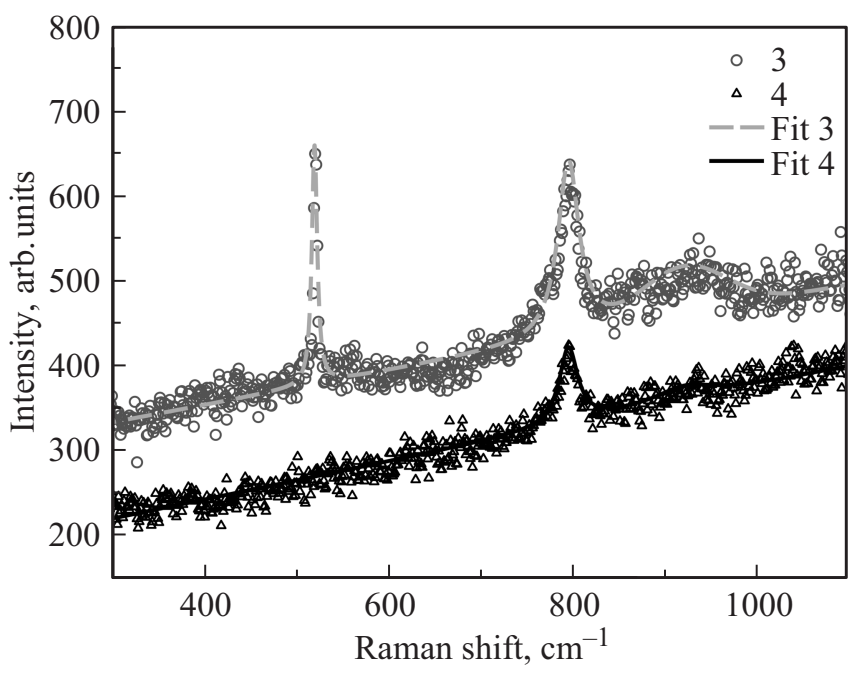

Рис. 3. Спектры КРС образцов 3,4 и результаты аппроксимации (Fit 3, Fit 4 соответственно).

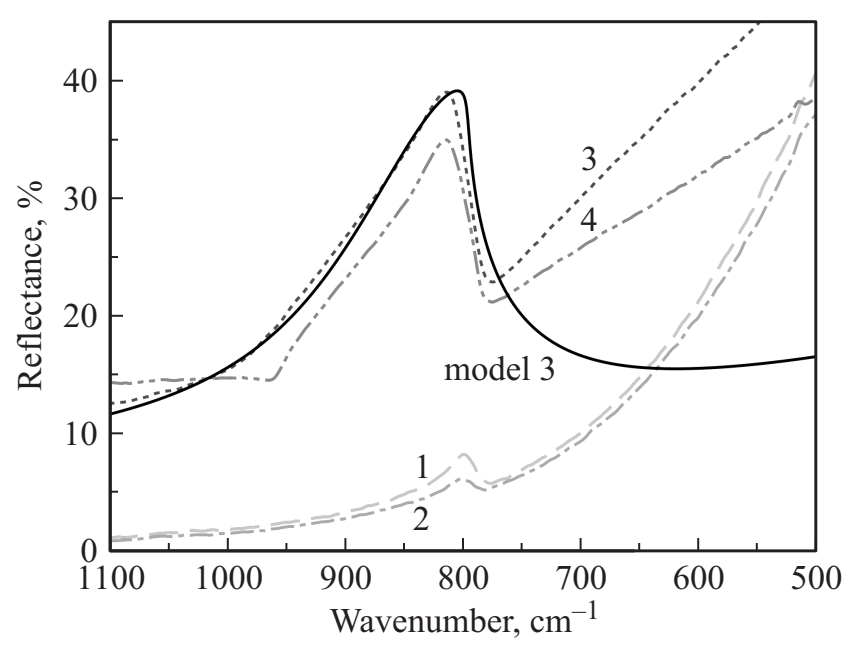

Рис. 4. Спектры ИК отражения образцов 1-4 (номера образцов указаны) и результат моделирования спектра отражения образца 3 (model 3). 
появление двухфононного пика следовало бы ожидать в районе $960 \mathrm{~cm}^{-1}$, а результат разложения спектра образца 3 показывает, что кривая имеет максимум в районе $920 \mathrm{~cm}^{-1}$ и полуширину $50 \mathrm{~cm}^{-1}$, как и для образца 1.

Согласно полученным оценкам положений максимумов и полуширин пиков и используя модель пространственного ограничения фононов [18], можно придти к выводу, что эффект пространственного ограничения фононов в исследованных наноструктурах $\mathrm{Si}$ и $\mathrm{SiC}$ отсутствует. Заметное уширение линии на $796 \mathrm{~cm}^{-1}$ может быть объяснено многочисленными дефектами упаковки кристаллической решетки и возникшими механическими напряжениями.

На рис. 4 представлены спектры отражения образцов 1-4 в среднем ИК диапазоне. Сначала рассмотрим поведение спектров отражения образцов 1 и 2. В области больших волновых чисел наблюдается сильное рассеяние, что проявляется в уменьшении сигнала отражения. Спектры отражения образцов 1 и 2 характеризуются монотонным ростом отражения от 1 до 40\% в диапазоне от 1100 до $500 \mathrm{~cm}^{-1}$. Такой рост, возможно, объясняется вкладом свободных носителей заряда в спектр отражения. Высокая концентрация свободных носителей заряда может быть объяснена появлением нестехиометрических дефектов в процессе формирования нанонитей $\mathrm{SiC}$. На фоне монотонного роста наблюдается пик в спектре отражения в районе $800-900 \mathrm{~cm}^{-1}$. Наличие этого пика объясняется взаимодействием падающего излучения с LO/TO-фононами $\mathrm{SiC}$ и соответствует полосе остаточных лучей. По наличию такой полосы и ее точному положению можно сделать вывод о том, что падающее ИК излучение отражается от кристаллического $\mathrm{SiC}$. Форма полосы остаточных лучей совпадает с формой полосы, которую имеет сильно легированный кристаллический $\mathrm{SiC}[19]$.

Рассмотрим спектры отражения образцов 3 и 4, также представленные на рис. 4. Отражение этих образцов характеризуется ростом с уменьшением волнового числа, аналогично поведению спектров коэффициента отражения образцов 1 и 2. Следует отметить, что этот рост не такой стремительный: отражение меняется от 12 до 50\% в указанном диапазоне для образца 3. Для образцов 3 и 4 в спектре также можно обнаружить полосу остаточных лучей, характерную для кристаллического $\mathrm{SiC}$. Эта особенность в спектре отражения выражена еще более ярко, чем для образцов 1 и 2. Чтобы объяснить такое поведение спектра отражения был выполнен расчет с использованием модели плазмон-фононного резонанса, описанной в работе [19]. Согласно этой модели диэлектрическая проницаемость рассчитывалась по формуле

$$
\varepsilon(\omega)=\varepsilon_{\infty}\left(\frac{\omega_{L}^{2}-\omega^{2}-i \Gamma \omega}{\omega_{T}^{2}-\omega^{2}-i \Gamma \omega}-\frac{\omega_{p}^{2}}{\omega^{2}-i \omega Y_{p}}\right),
$$

где $\varepsilon_{\infty}-$ высокочастотная диэлектрическая проницаемость, $\omega_{T}, \omega_{L}$ - частоты поперечных и продольных

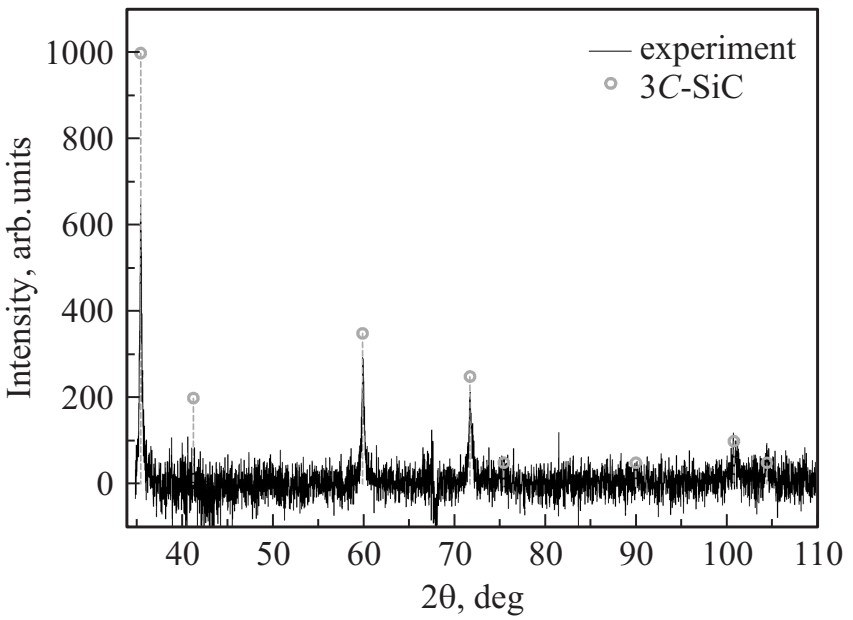

Рис. 5. Спектр рентгеновской дифракции нанонитей карбида кремния, отслоенных от образца 2.

оптических фононов, Г - константа затухания для ТО- и LO-фононов, которая в данном случае была одинаковой, $\omega_{p}$ - плазменная частота, $\gamma_{p}-$ константа затухания свободных носителей заряда.

Коэффициент отражения при нормальном падении дается выражением

$$
R(\omega)=\frac{(n-1)^{2}+k^{2}}{(n+1)^{2}+k^{2}},
$$

где $n-$ показатель преломления, $k-$ коэффициент экстинкции.

Результаты моделирования для образца 3 представлены на рис. 4. Видно, что удалось добиться хорошего совпадения формы полосы остаточных лучей, но в области малых волновых чисел экспериментальная зависимость имеет значительно более стремительный рост, который может быть объяснен дополнительным отражением от подложки $\mathrm{Si}$. C ростом волнового числа увеличивается рассеяние на шероховатой поверхности (см. рис. $1, b)$, поэтому отражение от подложки в этом диапазоне не проявляется. Выполненное моделирование позволяет сделать заключение о том, что наблюдаемое видоизменение полосы остаточных лучей можно объяснить только влиянием свободных носителей заряда. Оценка концентрации дает значение $\sim 10^{19} \mathrm{~cm}^{-3}$.

Для образца 2 удалось механически отслоить нанонити $\mathrm{SiC}$ от пористой кремниевой подложки. Они были исследованы методами спектроскопии КРС и рентгеновской дифракции. Данные спектроскопии КРС согласуются с тем, что получено для нанонитей на подложке и представлено на рис. 2. Результаты исследований методом рентгеновской дифракции представлены на рис. 5. Полезный сигнал оказался крайне слабый и накапливался в течение суток. Тем не менее отчетливо видны пики, соответствующие кубической модификации 3C-SiC. Эти данные подтверждают предположение, сделанное по данным спектроскопии КРС. 


\section{4. Обсуждение результатов и заключение}

Результаты исследований методами КРС и ИК спектроскопии указывают на кристалличность полученных нанонитей $\mathrm{SiC}$. Положение пика ТO-моды в спектрах КРС свидетельствует в пользу того, что это кубическая модификация $3 C$, но отсутствие в спектре LO-моды не позволяет сделать однозначный вывод. По данным ИК отражения невозможно определить кристаллографическую модификацию $\mathrm{SiC}$, но из вида спектра в области полосы остаточных лучей можно сделать вывод о высокой концентрации носителей заряда в нанонитях. Отметим, что спектроскопия ИК отражения ранее использовалась при исследовании пористых [20] и эпитаксиальных [21] слоев $\mathrm{SiC}$, однако в нашей работе впервые измерены спектры отражения от нанонитей $\mathrm{SiC}$. Метод дифракции рентгеновских лучей позволил сделать однозначный вывод о том, что исследуемые нанонити $\mathrm{SiC}$ имеют кубическую модификацию $3 C$. Оптические методы исследования являются неразрушающими и, имея высокую чувствительность, позволяют быстро по сравнению с методом рентгеновской дифракции обнаружить нанонити $\mathrm{SiC}$ на поверхности кремниевых наноструктур. Наличие высокой концентрации свободных носителей заряда в нанонитях делает их перспективными для использования в устройствах микроэлектроники, совместимых с кремниевой технологией. С учетом высокой механической, термической и химической стойкости проводящие нанонити $\mathrm{SiC}$ могут быть более привлекательными, чем наноструктуры чистого кремния, для применения в фотонике и молекулярной сенсорике.

Авторы выражают благодарность В.В. Снегиреву (физический факультет МГУ) за измерения рентгеновской дифракции и В.В. Подлипнову (СГАУ) за предоставленные СЭМ-изображения.

\section{Список литературы}

[1] Е. Обжерин. Электроника: Наука, Технология, Бизнес, 7, 22 (2009).

[2] В. Лучинин, Ю. Таиров. Наноиндустрия, 1, 36 (2010).

[3] E.W. Wong, P.E. Sheeban, C.M. Lieber. Science, 277, 1971 (1997).

[4] Z.S. Wu, S.Z. Deng, N.S. Xu, J. Chen, J. Zhou, J. Chen. Appl. Phys. Lett., 80, 382 (2002).

[5] Л.А. Головань, А.А. Соколов, В.Ю. Тимошенко, А.В. Семенов, А. Пастушенко, Т. Ничипорук, В. Лысенко. Письма ЖЭТФ, 101 (12), 891 (2015).

[6] С.А. Кукушкин, А.В. Осипов. ФТТ, 50 (7), 1188 (2008).

[7] С.А. Кукушкин, А.В. Осипов, Н.А. Феоктистов. ФТТ, 56 (8), 1457 (2014).

[8] Mingxia Lu, Ang Li, Tianhui Wang, Dan Wang, Weiping Qin. J. Nanosci. Nanotechnol., 10, 2135 (2010).

[9] В.В. Старков. Все материалы, 4, 13 (2009).
[10] А.А. Ищенко, Г.В. Фетисов, Л.А. Асланов. Нанокремний: свойства, получение, применение, методы исследования и контроля (М., Физматлит, 2011).

[11] В.И. Чепурнов. Патент РФ на изобретение № 2370851, дата рег. 20.10.2009.

[12] Н.В. Латухина, А.С. Рогожин, С. Саед, В.И. Чепурнов. Изв. вузов. Матер. электрон. техн., 4, 284 (2014).

[13] B.Q. Wei, J.W. Ward, R. Vajtai, P.M. Ajayan, R. Ma, G. Ramanath. Chem. Phys. Lett., 354, 264 (2002)

[14] В.Л. Кузнецов, А.Н. Усольцева, И.Н. Мазов. Рос. хим. журн., 48 (5), 37 (2004).

[15] А.И. Харламов, Н.В. Кириллова, С.Н. Каверина. Теор. эксперим. химия, 38 (4), 232 (2002).

[16] S. Nakashima, H. Harima. Phys. Status Solidi A, 162, 39 (1997).

[17] Xinfa Qiang, Hejun Li, Yulei Zhang, Song Tian, Jianfeng Wei. Mater. Lett., 107, 315 (2013).

[18] H. Campbel, P.M. Fauchet. Solid State Commun., 58, 739 (1986).

[19] K. Narita, Y. Hijikata, H. Yaguchi, S. Yoshida, S. Nakashima. Jpn. J. Appl. Phys., 43 (8A), 5151 (2004).

[20] J.Y. Fan, H.X. Li, W.N. Cui. Appl. Phys. Lett., 95, 021906 (2009).

[21] Lin Dong, Guosheng Sun, Liu Zheng, Xingfang Liu, Feng Zhang, Guoguo Yan, Wanshun Zhao, Lei Wang, Xiguang Li, Zhanguo Wang. J. Phys. D: Appl. Phys., 45, 245102 (2012).

Редактор Л.В. Шаронова

\section{Structural and optical properties of silicon carbide nanowires fabricated by high temperature carbonization of silicon nanostructures}

\author{
A.V. Pavlikov ${ }^{1}$, N.V. Latuhina ${ }^{2}$, V.I. Chepurnov' ${ }^{2}$, \\ V.Yu. Timoshenko $1^{1,3}$ \\ ${ }^{1}$ Lomonosov Moscow State University, \\ (Faculty of Physics), \\ 119001 Moscow, Russia \\ 2 Samara State Aerospace University, \\ 443086 Samara, Russia \\ ${ }^{3}$ National Research Tomsk State University, \\ 634050 Tomsk, Russia
}

\begin{abstract}
During high temperature carbonization of porous silicon and silicon nanowires the threadlike structures of silicon carbide $(\mathrm{SiC})$ were obtained with diameters of $40-50 \mathrm{~nm}$, that were studied by scanning electron microscopy, $X$-ray diffraction, Raman spectroscopy and infrared reflection. The results of $X$-ray diffraction and Raman spectroscopy evidence that cubic 3C-SiC polytype dominates in the investigated samples. The shape of the reststrahalen band near $800-900 \mathrm{~cm}^{-1}$ in the infrared reflection spectra indicates the presence of free charge carriers. The possibility of utilizing the obtained $\mathrm{SiC}$ nanowires in devices for microelectronics, photonics and gas sensing is discussed.
\end{abstract}

